\title{
The Strength Analysis of CFM56 Engine Blade
}

\author{
Zhenzhen Liu', Zhixiong Chen ${ }^{2}$, Jin Chen ${ }^{1}$ \\ ${ }^{1}$ Nanchang Hangkong University School of Aircraft Engineering, student, 2017, China \\ 2 Shanghai University of Engineering Science School of Automotive Engineering, associate professor,2017, China
}

\begin{abstract}
Aero engine is a kind of thermodynamic machinery,which require have strict aerodynamic load, mechanical load and strong durability, its longevity depends largely on the life of its main components. In this paper, a series of studies are carried out on the strength of fan blades of CFM56 engine, which provide a reference value for improving the reliability of the engine. The finite element model of the engine fan is established by using CATIA's finite element software. The centrifugal stress distribution of the fan at different speeds and the influence of torque on fans under different speeds are calculated respectively, and the static strength of the fan is checked.
\end{abstract}

\section{Introduction}

The CFM56 is a high ratio bypass turbofan engine, which is based on F101 core technology, to meet the needs of the international military and civilian aircraft market in late 1980s, developed by CFM international (CFMI)company,which is composed by American GE Corporation and the French SNECMA company. Since its first model CFM56-2 acquired the airworthiness certificate in November 1979, by 2005, it has developed to 6 Series: CFM56-3, CFM56-5A, CFM56-5B, CFM565c, CFM56-7 and so on, a total of 28 models, whose thrust has covered $71 \sim 151 \mathrm{kN}$, and has become the driving force of 22 types of aircraft.By February 2005, the use of each type of CFM56 engine reached 14553, and the cumulative working time of the engine was 274511467 flight hours and 161778396 cycles. At present, there are 5796 aircraft powered by CFM56, with an average of one aircraft taking off every 4 seconds. At the same time, about 800 CFM56 engines are used in our country.

Aeroengine is the power device of an aircraft, and it is known as the "heart" of the aircraft, so the fan is one of the important components of turbofan engine, and its performance directly affects the performance of the whole engine. The air behind the fan is divided into two roads. One road is the outer culvert, and the other is connotation.

\section{The stress calculation of fan blade}

Because the structure, loading and restraint conditions of fan blades are all spatial properties, so it is necessary to do the finite element analysis of fan blades, before calculating the stress of fan blades under centrifugal load.
The precondition of the elastic stress analysis of the blade line are as follows[1][2]:

(1)The deformation of the blade is small when working. In general, the size of the deformation is not predetermined in advance and can only be estimated by experience. From the existing engine, the fan blade has smaller deformation, which can be considered to meet the requirements of small deformation.

(2)The material of the blade has not yielded at work, that is, within the elastic range. At present, most of the engine blades are designed with elastic, which can meet this requirement.

(3)There are no contact between the blades or between the blades and other parts. So, the blades are discussed in this paper does not include the tenon part, and do not consider the adjacent crown and shoulder the contact vibration.

When the blade is discretized, the stress changes in a relatively large area, such as near the hub, more dense grid should be, and in the stress change of relatively small area, such as the near tip, can share some sparse grid, it should be noted that, when the unit are divided, the size of the unit's direction should be similar, and try to make the angle of each unit is small, so as to ensure that each unit has a good character.

\subsection{Three dimensional fan model}

According to the CFM56 engine, the fan model is set up in the 3D design software CATIA, as shown in figure 1.

The material used in the calculation is steel, and the material parameters are shown in table 1.

\subsection{Finite element mesh of the fan}


All the units are hexahedral units, and the size of the fan is $50 \mathrm{~mm}$. Because of the strength calculation of the fan blades, so the size of the blades of the mesh fan blades is $20 \mathrm{~mm}$. The mesh is divided into 57403 units and 18459 nodes by using the mesh division tool in CATIA software, as shown in figure 2.

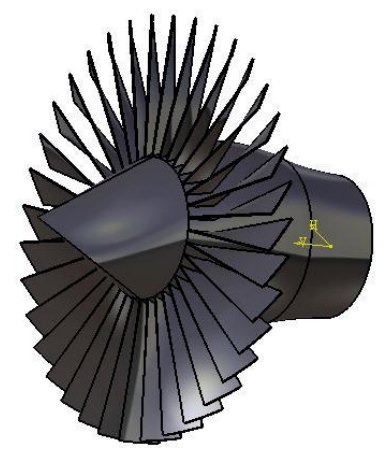

Figure 1. Fan model of CFM56 engine

Table 1. Physical parameters of steel

\begin{tabular}{|c|c|}
\hline Material & Steel \\
\hline Young's modulus & $2 \mathrm{E}+011 \mathrm{~N} \cdot \mathrm{m}^{2}$ \\
\hline Poisson's ratio & 0.266 \\
\hline Density & $7860 \mathrm{~kg} \cdot \mathrm{m}^{3}$ \\
\hline Coefficient of thermal expansion & $1.17 \mathrm{E}-005 \mathrm{kdeg}$ \\
\hline Yield strength & $2.5 \mathrm{E}+008 \mathrm{~N} \cdot \mathrm{m}^{2}$ \\
\hline
\end{tabular}

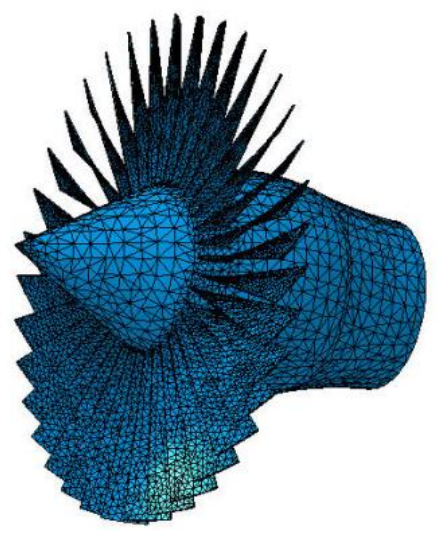

Figure 2. Finite element mesh of fan

\subsection{Calculation of load and boundary conditions}

\subsubsection{Load characteristic of blade}

The fan blades rotate around the engine axis at working, and the loads are included in the centrifugal force, aerodynamic force and thermal load.
The aerodynamic force is a kind of surface distribution pressure, it exerts effect on each surface of the blade, but it is not evenly distributed, its distribution along the leaf height direction and leaf width direction are not uniform,the aerodynamic field can be calculated accurately by the cascade passage and 3D flow field, but it is a larger workload. In general, aerodynamic forces should be taken into account when stress analysis is performed on the blade, but sometimes it can not be considered due to the lack of relevant data. The centrifugal stress on the fan blade is much larger than the aerodynamic stress,so ignoring the aerodynamic force has little effect on the analysis results.

Centrifugal force is a volumetric force, which is directly proportional to the mass, radius and the square of speed. It mainly causes the blade to generate radial tensile stress, which at the same time produces twisting stress for the twisted blade. The thermal load is generated when the blades are heated and the deformation of each part is restricted. Thermal stress generated by thermal load is not only related to the temperature gradient of the blade but also related to the geometric constraints on the blade. The larger the temperature gradient of the blade, the tighter the geometric constraint, the greater the thermal stress. Therefore, the thermal load is usually described by the temperature field and is closely related to the geometric boundary conditions. Strictly speaking, all the blades have the effect of thermal load, but for the fan blade, due to low temperature and uniform temperature distribution, and the thermal stress is not large, so the stress analysis is often neglected.

\subsubsection{Analysis and calculation of centrifugal force}

It is known by 2.3.1 that the stress analysis of the blade only needs to consider the influence of the centrifugal force. So this paper only calculates and analyzes the strength of the fan blade under the centrifugal load. The deformation and stress of the fan blade are calculated by the software CATIA.The rated speed of the fan is 14460 $\mathrm{r} / \mathrm{min}$, In order to analyze the stress distribution of fans at different speeds, three speeds of $8000 \mathrm{r} / \mathrm{min}, 14460 \mathrm{r} / \mathrm{min}$ and $20000 \mathrm{r} / \mathrm{min}$ are analyzed.The finite element software CATIA is used to analyze the stress at different speeds, as shown in Figure 3 to 4.

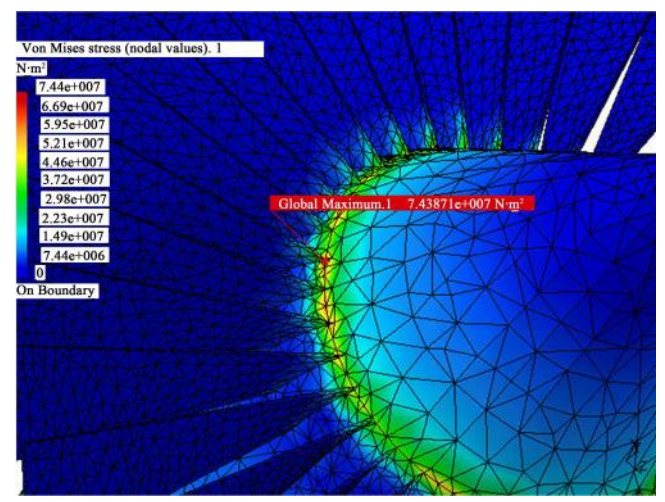

Figure 3. The stress distribution of fan at $8000 \mathrm{r} / \mathrm{min}$ 
From figure 3-4, we can see that when the speed is $8000 \mathrm{r} / \mathrm{min}$, the stress of the fan is concentrated on the root of the blade, the maximum stress of the blade is 74.4MPa, the deformation displacement appears at the tip of the leaf, and the maximum radial displacement of the leaf tip is about $0.208 \mathrm{~mm}$.Likewise, when the speed is $14460 \mathrm{r} / \mathrm{min}$, the stress of the fan is concentrated on the root of the blade, the maximum stress of the blade is 398.2MPa, the deformation displacement appears at the tip of the leaf, and the maximum radial displacement of the leaf tip is about $0.713 \mathrm{~mm}$. Similarly,when the speed is $20000 \mathrm{r} / \mathrm{min}$, the stress of the fan is concentrated on the root of the blade, the maximum stress of the blade is 614.1MPa, the deformation displacement appears at the tip of the leaf, and the maximum radial displacement of the leaf tip is about $1.0948 \mathrm{~mm}$.

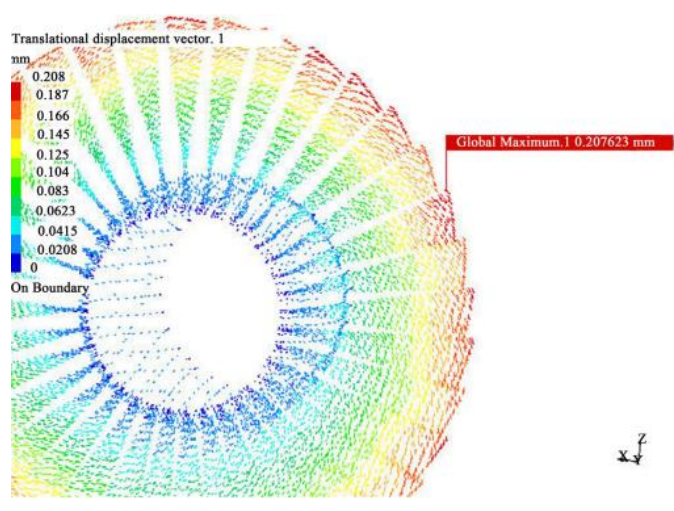

Figure 4. The stress deformation of fan at $8000 \mathrm{r} / \mathrm{min}$

From the above we can see that under different speeds, the fan's force is basically the same, the stress of the fan is concentrated on the root of the blade,the deformation displacement appears at the tip of the leaf. The greater the speed is, the greater the force of the blade is, the greater the radial displacement of the blade is.

\subsubsection{The effect of the torque}

Under the action of the centrifugal force field, the fan blade is not only stretched, but also bears the torsional torque to restore the torque. The larger the blade twist is, the greater the recovery torque will be. The torsional deformation of the blade will cause torsional shear stress on the cross section of the blade and redistribute the tensile stress on the cross section of the blade. In 2.3.2, the influence of centrifugal force is only considered.The influence of torque is not considered. The influence of torque on fan blades is analyzed separately here, and a torque is added to the fan blades. The specific method of calculating torque according to the rated speed of the fan is as follows:

\section{$\mathrm{T}=9550 * \mathrm{P} / \mathrm{n}$}

In the formula, $\mathrm{T}(\mathrm{N} ; \mathrm{m})$ is torque; $\mathrm{P}(\mathrm{kW})$ is power; the power in this article is $1800 \mathrm{~kW} ; \mathrm{n}(\mathrm{r} / \mathrm{min})$ is the speed, here the rated speed is $14460 \mathrm{r} / \mathrm{min}$. The torque of the fan at the rated speed is $1189 \mathrm{~N} \cdot \mathrm{m}$. Three different torques are applied to the fan for analysis,and the stress diagram is shown in figure 5-6.
It can be seen from Figure 5-6 that when the torque is $800 \mathrm{~N} \cdot \mathrm{m}$, the stress of the fan is concentrated at the root of the blade. The maximum stress of the blade is 4.32 $\mathrm{MPa}$. The deformation displacement appears at the tip of the fan blade. The maximum radial displacement of the blade is about $0.127 \mathrm{~mm}$.

Likewise, when the torque is $1189 \mathrm{~N} \cdot \mathrm{m}$, the stress of the fan is concentrated at the root of the blade. The maximum stress of the blade is $6.4 \mathrm{MPa}$. The deformation displacement appears at the tip of the fan blade. The maximum radial displacement of the blade is about $0.327 \mathrm{~mm}$.Similarly, when the torque is 1500 $\mathrm{N} \cdot \mathrm{m}$, the stress of the fan is concentrated at the root of the blade. The maximum stress of the blade is $8.11 \mathrm{MPa}$. The deformation displacement appears at the tip of the fan blade. The maximum radial displacement of the blade is about $0.237 \mathrm{~mm}$.

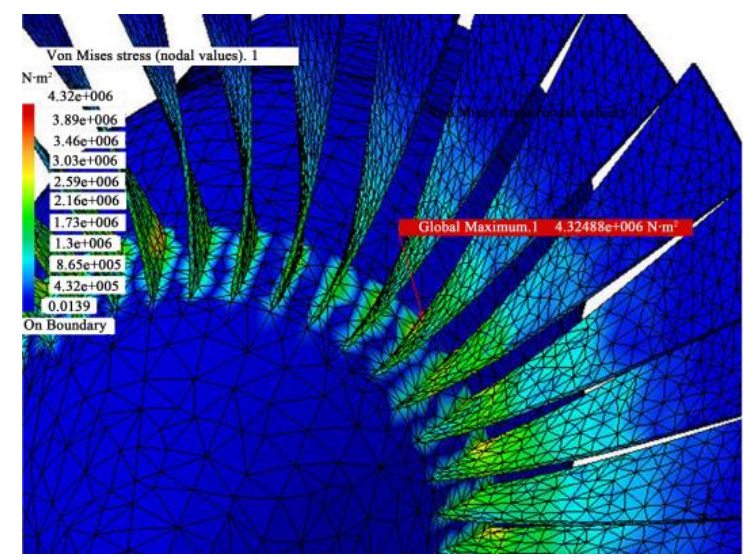

Figure 5. The stress distribution of fan at $800 \mathrm{~N} \cdot \mathrm{m}$

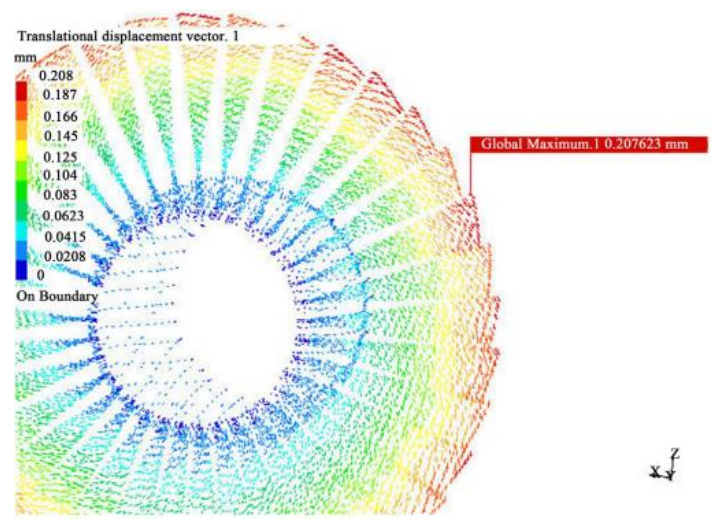

Figure 6. The stress deformation of fan at $800 \mathrm{~N} \cdot \mathrm{m}$

From the foregoing, the force under different torque of the fan is basically the same, and the maximum stress position appears at the root of the blade, the maximum displacement deformation appears at the tip of the blade. Under the rated speed, the maximum radial displacement of the blade tip is $0.327 \mathrm{~mm}$., The greater the torque, the greater the stress, the stress position is basically the same.

According to the calculation results of 2.3.2 and 2.3.3, the maximum stress of fan appears at the root of the blade when working, and the maximum stress of fan is $404 \mathrm{MPa}$ 
at the rated speed. According to the Spey engine stress standard (EGD-3) [3] [4], the fan as a key component of the aero-engine,which must be checked for the static strength of the blade in order to prevent various failures. Spey engine stress standards are: under all normal operating conditions, the average circumferential stress of the turbine disk does not exceed $75 \%$ of $\sigma_{0.1}$, under centrifugal and thermal loads, the circumfer- ential stress at the inner diameter does not exceed $95 \%$ of $\sigma_{0.1}$ [5]. In this paper, the yield strength of the fan at the design speed is $750 \mathrm{MPa}$, while the maximum stress of the fan at the rated speed is $404 \mathrm{MPa}$ and less than $95 \% \sigma_{0.1}$. Therefore, in this calculation condition, the turbine disk satisfies EGD-3 Static strength design requirements.

\section{Conclusions}

In this paper, CATIA's own finite element software is used to analyze the stress of CFM56 engine fan blades under centrifugal load. From the analysis results, it can be seen that the maximum point of deformation occurs at the tip of the fan and the high stress area appears in the root area of the blade.Under rated power, the maximum Von Mises stress caused by rotary centrifugal force is 398 $\mathrm{Mpa}$, the stress caused by rotating torque is $6.4 \mathrm{MPa}$, and the maximum stress is superimposed on $404.4 \mathrm{MPa}$.The stress induced by torque is very low relative to the stress caused by centrifugal force. The stress of the fan under normal working condition is mainly caused by centrifugal load.

The fan is the key technology of civil high bypass ratio turbofan engine, In the future, the direction of the research includes the curved blade, the stirrup blade and the separated blade.Noise reduction, resistance to external damage and blade tolerance are also the key problems in the design of large fans [6].The key technology includes: unsteady viscous aerodynamic design technology; splitter blade design; swept fan blade design and manufacturing technology; blisk design and manufacturing technology; two flow control technology; brush seal design and manufacturing technology; the design of metal matrix composites.

The design of the future fan is mainly to continue improving the flow capacity, the blade tip cutting speed and the average level load.To improve the flow capacity can reduce the engine inlet diameter, so as to effectively reduce the weight of the engine, improve the thrust weight ratio. The method is to reduce the hub ratio (d) and increase the axial Maher number (Ma).At present, in the design of the fan, the wheel hub ratio is 0.34 , and the Maher number is 0.631.Increasing the tangential speed and diffusion factor of blade tip can improve the stage pressure ratio, thereby reducing the required series under the given total pressure ratio and reducing the length and weight of the whole engine.

In recent years, with the continuous improvement of computer computing speed, finite element analysis has gained more and more attention in engineering design and analysis, and has become an effective way to solve complex engineering problems. Almost all of the design and manufacturing can not be separated from the finite element analysis and calculation.

\section{References}

1. LV Q. Strength analysis and life calculation of torque converter blades based on fluid-solid interaction. [D]. Nanjing. Nanjing University of Aeronautics and Astronautics, 2014.

2. Hou J D, Chen S X. Strength analysis of wide-chord fan blade from an aero engine[J].Aeronautical Computing Techniue, 2015,45 (2): 10-12.

3. $\mathrm{Fu}$ N. Strength analysis and life calculation of turbine disk and blade of an aero engine [D].Xi'an: Journal of Northwestern Polytechnical University, 2006.

4. Yu D Z, Wen D H, Zhang H R. Structural static analysis of gas turbine blade and disk of an aeroengine $[\mathrm{J}]$. Structure \& Environment Engineering. 2012, 39 (4):32-39.

5. Zhang M Q. Static strength calculation and analysis of the first stage turbine blade of turboprop six engine[J]. Journal of Civil Aviation University of China. 1983,1 (1): 29-39.

6. Wang C J, Song S G, Zong X. Vibration analysis of the blade disc coupled structure of compressor[J]. Journal of Aerospace Power. 2007,22 (7): 1065-1068. 